\title{
Work and Nonwork Predictors of Employees' Retirement Ages
}

\author{
Terry A. Beehr and Sharon Glazer \\ Central Michigan University \\ Norma L. Nielson \\ Management Department, University of Calgary, Calgary, Alberta, Canada \\ and
}

Suzanne J. Farmer

Central Michigan University

\begin{abstract}
In a study of the likely causes of retirement decisions, 197 older employees of a state government and their spouses were surveyed as they were getting ready to retire. Data also were collected from the employees' personnel records. Holding finances, gender, and health constant, a set of work characteristics (especially being tired of working) and a set of nonwork characteristics (personal characteristics and expected retirement activities) that were conceptualized as potentially inducing employees to retire each provided a unique contribution of about $10 \%$ of the variance to expected retirement age. (๑) 2000 Academic Press
\end{abstract}

Key Words: retirement; older workers.

The average age of the American population has been steadily increasing in recent years and is projected to continue doing so for some time (Fullerton, 1991). There have been dramatic increases in the number of workers retiring "younger" in recent years (Feldman, 1994), resulting in a decreasing work force participation rate by people over the age of 55 (Sum \& Fogg, 1990). Although

The data were collected with the funding of a grant from the Andrus Foundation. Further tangible assistance was provided by a sabbatical leave and an associated grant from the Faculty Research and Creative Endeavor Committee of Central Michigan University. The authors appreciate the help of those agencies. We also thank Sonja Faulkner and Papia Ghosh for their assistance on this project. A previous version of this paper was presented at a meeting of the Midwestern Psychological Association.

Address correspondence and reprint requests to Terry A. Beehr, Program in Industrial/ Organizational Psychology, Life-Span Development Research Center, 101 Sloan Hall, Central Michigan University, Mt. Pleasant, MI 48859. 
voluntary retirement may be desired by the individuals themselves, this poses the potential dilemma of a larger retired population relative to the working population, who bear the primary economic burden of supporting society. In addition to effects of retirement on society as a whole, specific organizations experiencing large numbers of retirements necessarily experience a simultaneous shift and change of their workforces, for better or for worse. Simply replacing a significant number of an organization's workers each year can be a costly and timeconsuming process for human resources managers. Both organizations and the larger society, therefore, have a stake in the collective retirement decisions of numerous individuals, and it is useful for all parties to understand the nature of retirement and retirement decisions.

The current study examines potential influences on employees' decisions to retire that reside both in the work situation and in their nonwork lives. Both of these domains of people's lives have been suggested as possible causes of retirement decisions (e.g., Beehr, 1986; Feldman, 1995; Taylor and Shore, 1995). There has been little research on the work-related factors, however, and workand nonwork-related factors have not been studied systematically together in the same study. Relevant research and theory is reviewed here, suggesting that retirement decisions may be affected by seven work-related variables (autonomy, skill variety, task significance, interaction with others, workforce reductions, organizations' retirement incentives, and being tired of working) and eight variables in life's nonwork domain (availability of health insurance, needing to care for someone else, a legal mandatory retirement age, and five expected retirement activities).

The nature and definition of retirement has been changing in recent years, so that retirement does not necessarily mean total and permanent withdrawal from paid work (Beehr, 1986; Feldman, 1994; Lawson, 1991; Talaga and Beehr, 1989). Many retirees now work full or part time, often for themselves or a new employer, and either in the same or a new occupation (Lawson, 1991). The division between work and retirement is, therefore, not totally distinct. Partly because of this, retirement has had many specific operational definitions in past research (Beehr, 1986; Talaga and Beehr, 1989), but most fit within the general conceptual definition offered by Feldman (1994). Retirement is "the exit from an organizational position or career path of considerable duration, taken by individuals after middle age, and taken with the intention of reduced psychological commitment to work thereafter" (p. 287). Each part of this definition is important. Retirees are (1) older people with (2) some cohesive past work pattern (3) for a sustained period of time and (4) with reduced psychological investment in work.

Reviews of research on the predictors of retirement decisions consistently conclude that finances, in some form or other, are the strongest single predictor of the decision to retire (e.g., Beehr, 1986; Robinson, Coberly, and Paul, 1985; Talaga and Beehr, 1989; Taylor and Shore, 1995). In other words, people are generally more likely to leave the workforce if they can financially afford to retire 
than if they cannot. Other factors are almost always less salient in predicting retirement. One occasional exception is health, either mental or physical. Poor health has been a moderately strong, consistent theoretical and empirical predictor of retirement. After finances, it is the variable most often cited in the literature as a predictor of retirement (Talaga and Beehr, 1989; Taylor and Shore, 1995), although there have been a few studies failing to find this result.

One question receiving recent attention in the empirical research on retirement concerns the categories of variables that predict retirement decisions. Determining the ways in which different sets of predictors influence retirement decisions can help us understand the forces on older employees. Shultz, Morton, and Weckerle (1998) examined the dichotomy of push (generally aversive) factors and pull (generally pleasant) factors that lead to voluntary versus involuntary retirement. A recent study of a national sample of older Americans, however, suggests another dichotomy that makes intuitive sense and could have some applied utility. Stetz (1998) found that the reported reasons for retirement factored into work-related and nonwork-related dimensions. Of these, the domain of variables receiving surprisingly little research regarding its relevance in retirement decision-making is the workplace itself and the job in particular.

\section{WORK-RELATED CHARACTERISTICS AND RETIREMENT}

Logically, characteristics of employees' jobs could predict retirement proclivity by making the job repulsive or onerous in some way. Unfavorable work situations would repel workers away from work and toward retirement (Beehr, 1986; Taylor and Shore, 1995). For example, people who have jobs with little autonomy, skill variety, task significance, or poor social relationships may be more inclined to retire than someone who has an intrinsically interesting and motivating job. The unfavorable job conditions that push people toward retirement also can push them to search for a better job with a different firm, if they can find one. Older workers, however, often have retirement as another alternative.

As noted earlier, retirement is considered a withdrawal (from work) behavior. This was accentuated in studies by Hanisch and Hulin (1990); 1991), presenting factor analytic evidence supporting the notion that retirement is part of a larger construct of employee withdrawal behaviors that includes turnover. A recent study, however, highlights unique differences between retirement and turnover (Adams and Beehr, 1998). Such withdrawal has long been considered to the partially dependent on the nature of the work. Cotton and Tuttle (1986) found that three quarters of the published studies report a link between dissatisfaction with work and turnover, and Steers and Rhode's (1978) well-known model of absenteeism includes job (dis)satisfaction as a prominent predictor. If retirement, like turnover and absenteeism, is a withdrawal behavior, people who are dissatisfied with their jobs would be particularly likely to retire.

Contrary to this expectation, however, reviews have generally found research that either did not examine the ability of job satisfaction to predict actual 
retirement behaviors or reported a lack of association (Beehr, 1986; Robinson, Coberly, and Paul, 1985; Talaga and Beehr, 1989). One article by Hanisch and Hulin (1990), for example, reported nonsignificant zero-order correlations in two different samples between actual retirement age and their three job satisfaction facet indices. Instead, only the desire to retire was correlated with some of the facet satisfactions. In a second study, Hanisch and Hulin (1991) found that intended age of retirement was significantly correlated with only one of three facet satisfactions (i.e., work itself), and the percentage of variance accounted for by the correlation was only $3 \%$. Again, the desire to retire was correlated with more of the job satisfaction indices than the intended age of retirement, and actual retirement age was not shown to correlate with job satisfaction at all. Finally, another recent study found no relation between intention to retire in the near future and job satisfaction (Adams and Beehr, 1998). Overall, research to date leads to the conclusion that job satisfaction is not a significant predictor of actual retirement behaviors. Thus, the search for work-related predictors of retirement must look to additional factors.

The Steers and Rhode's (1978) absenteeism model suggests that task and social characteristics of jobs are related to absenteeism. A few studies have also suggested a relationship between specific or perceived job-related characteristics and the decision to retire. For instance, McCune and Schmitt (1981) found that intrinsically motivating job characteristics such as autonomy and variety are negatively related to retirement decisions. That is, the more autonomy or skill variety one perceives on the job, the less likely it is that he or she will decide to retire. Another study (Hayward and Hardy, 1985) reported that the opportunity to work with others on one's job was negatively related to the decision to retire, and therefore attraction and commitment to others in the work place may lessen a desire to retire. Thus, the little research to date on work-related variables predicting retirement suggests that a lack of two sets of factors in one's job may induce people to retire: some intrinsically motivating task characteristics and social factors in the workplace. This is consistent with another withdrawal behavior, i.e. absenteeism. This study investigated these possible predictors of retirement.

In addition to social and task characteristics, the rumor of cutbacks and/or layoffs may provide a salient motive for an employee to seek retirement. This threat of job loss is often coupled with a one-time retirement incentive from the organization in an effort to induce "voluntary" attrition, thereby easing the formidable task of down-sizing. For example, employees may feel forced into early retirement, reasoning that they would rather leave the workplace, collecting a retirement bonus in addition to their existing pension and benefits, than remaining in their job while living in fear of being laid off.

Finally, just plain being tired of work seems a simplistic, yet potentially important, factor pushing employees toward retirement. It is not difficult to fathom employees' desires to abdicate their working duties, especially after toiling for a considerable amount of their lifetime. Therefore, this work-related 
factor and also cutbacks, employer incentives, social factors, and some intrinsically motivating task characteristics are expected to influence an employee's decision to retire.

\section{NONWORK CHARACTERISTICS AND RETIREMENT}

While it is conceptually possible for the characteristics of a job to induce people to retire, it is just as likely that there are some characteristics of nonwork or retirement life that might have a similar effect, and some research has shown this (e.g., reviews by Beehr, 1986; Feldman, 1994). That is, some things outside of the work environment, and consequently about retirement, may be viewed as favorable and attractive by older employees, thereby influencing their decision to retire. These favorable retirement factors are reflective of leisure activities one expects to engage in during retirement years and perhaps even employment interests elsewhere. In addition, because nonwork factors can be either positive or negative, there may be some personal obligations that are calling the individual to leave work. For example, having to care for a sick family member might be aversive, but the ill person may still be drawing the older employee toward retirement. This would be similar to Steers and Rhodes' (1978) "ability to attend" category of predictors of absenteeism, again showing some of the similarity retirement has to other forms of work withdrawal. Aside from the ability to remain on the job, there is the possible attraction of retirement. For example, the excitement of engaging in personal hobbies may be an attractive or a positive nonwork factor in one's decision to retire. In either case, however, something outside the workplace is inducing retirement.

This study also examined the types of activities employees expected to engage in after they have retired. In retirement, people may expect to do more socializing with or traveling with family and friends, for example, and this might be an attraction of retirement. In addition, or alternatively, expected retirement activities might include developing new interests and skills with formal instruction or on one's own, finding new careers or just part-time jobs, engaging in avocations, or just plain taking it easy. These expected retirement activities represent some of the variables of expected retirement life that might induce employees to retire.

In addition to the potential lure of expected retirement activities, other characteristics of employees' environments outside the workplace might be considered to move them toward retirement. Some of these predictor variables may be considered personal characteristics, including having a family member who needs care (previously noted), reaching mandatory retirement age (where applicable), and the availability of affordable health insurance. For example, employees might be drawn into retirement if they were responsible for the care of a needy family member, physically or emotionally; or if they felt financially responsible for others, they might continue working. One study reported the particular alternative chosen (retire or keep working) depended on sex differences (Talaga and Beehr, 1995). Women were more likely to retire if they needed to care for someone, while men were more likely to keep working. This was only 
true for a subjective report that they were retired, however, and not for a retirement measure that included receiving a pension.

Finally, the availability and cost of continued health insurance may prove a predictive factor in understanding the decision to retire. After retirement, most employees are highly motivated to qualify for and provide their own health insurance, simply because most older individuals anticipate illness in their older years. If insurance is readily available and inexpensive, employees may be more favorably disposed toward retirement because they no longer require the shelter the organization's health insurance provides them.

In summary, this study attempts to predict employee retirement by identifying the potential influences in the work situation and the potential forces of nonwork or expected retirement life. As suggested by some previous writers (Beehr, 1986; Feldman, 1994; Taylor and Shore, 1995), it was expected that both domains, work and nonwork, would predict the decision to retire. Furthermore, it was expected that both domains could exert these effects while controlling the influences of finances, health, and gender. Since finances and health have been the strongest and most consistent predictors of retirement in past research, the predictive power of the other variables were examined holding these two constant, as well as gender. Finally, the study also represents an attempt to examine a variety of specific types of (expected) retirement activities as affecting retirement decisions. Retirement can be seen as a form of employee withdrawal from work, and in this study some of its predictor categories are similar to categories of predictors of other forms of employee withdrawal. Many of the specific predictors in these categories, however, are different from predictors of absenteeism and turnover, e.g., retirement activities, pension plans, and mandatory retirement laws.

\section{METHOD}

\section{Participants}

Participants were 197 employees of a western state in the United States who had completed information on all the study's variables. Most of the participants (87\%) expected to retire in less than 1 year. Their mean age was 59.2 years, and their mean expected age of retirement was 59.4 years. Sixty-two percent were males, $99 \%$ were white, and the majority had some graduate education (54\%). Job titles included teachers, professors, administrators, and various professionals. They were married on average for 32.1 years.

This study was part of a larger project that examined the financial well being of spouses who survive the deaths of retirees (Nielson and Beehr, 1994). All state employees who were intending to retire soon attended a retirement counseling session that focused on financial planning. The 452 married state employees intending to retire within several months and their spouses were asked to participate, and 440 couples initially agreed. Each received a mail-back questionnaire. 


\section{Measures}

Data were obtained from the employees' questionnaire, the spouses' questionnaire, and personnel records. A methodological study from another subsample of the data consisting of 161 respondents examined correlations and mean differences between three of the work-related variables (autonomy, variety, and task significance of the job) and five nonwork-related variables regarding expected retirement activities (social, growth, passive, tinkering, and employment) measured both before and after retirement (Beehr and Nielson, 1995). That study concluded that these eight measures were generally psychometrically sound, especially the job characteristics measures. That subsample included all respondents for whom there were data on the study's eight variables both before and after retirement. The present study attempts to predict retirement, and it includes all respondents for whom there are complete data on its 19 variables measured before retirement. About two thirds of the respondents in the present sample were also in that sample.

The criterion: age of retirement. Employee's self-reported expected age of retirement, made at the time of the questionnaire administration, was the criterion variable. Those who choose to retire "young" might do so because they find retirement more attractive (or the job less attractive), which fits with the purpose of this study. As noted earlier, other studies have also used this type of retirement variable as a criterion (e.g., Adams and Beehr, 1998; Erdner and Guy, 1990; Gibson, 1993; Hanisch and Hulin, 1990, 1991; Taylor and Shore, 1995).

Predictors. As noted in the introduction, the predictor variables were chosen based on suggestions in previous empirical and theoretical literature (Beehr and Nielson, 1995; Feldman, 1994; Talaga and Beehr, 1995; Taylor and Shore, 1995). These variables can be classified into three types: work-related variables, nonwork-related variables, and the control variables that were held constant (wealth, gender, and health).

The work-related variables included three of the Job Diagnostic Survey (JDS; Hackman and Oldham, 1976, 1980) indices that are thought to be intrinsically motivating, autonomy, skill variety, and task significance, and one of the social JDS indices, required interaction with others. These four variables used the JDS' regular seven-point Likert-type scales. As reported elsewhere (Beehr and Nielson, 1995), coefficient alphas for autonomy ( $\alpha=.67)$, variety $(\alpha=.59)$, task significance $(\alpha=.54)$, and interaction $(\alpha=.53)$ were somewhat low, but their test-retest correlations on a subset of these participants over a 6 -month period were $.71, .74, .45$, and .56 , respectively. These correlations were between reports about the job before and after retirement, which means the second report was of a memory of the former job rather than a description of a current job again. Considering this, and the fact that the absolute mean differences from the first to the second report were extremely small and nonsignificant, Beehr and Nielson concluded that the measures were psychometrically sound.

In addition, three other work-related variables measuring specific forces to- 
ward retirement were included as single-item measures: workforce cutbacks or layoffs, being tired of working, and a one-time retirement incentive offer from the employer. These items were rated on a four-point scale: 1, "Not important;" 2, "Slightly important;" 3, "Moderately important;" and 4, "Very important." Employees were asked to indicate "how important each item has been in your decision to retire."

The nonwork-related factors included a variety of items in which employees indicated the importance of various personal factors in their decision to retire. The personal variables included having a family member who needs care, reaching mandatory retirement age, and cost and availability of continued health insurance. It should be noted that the data collection occurred after the passage of the United States law eliminating mandatory retirement ages, but before the expiration of a window of time during which many state employees' pension plans were exempted from the law while the states increased their mandatory retirement age to 70 . Therefore this possible retirement predictor needed to be assessed, because it could have applied to some of these (state) employees. These personal variables were single items from the employee's questionnaire, ascertaining outside forces that led them to make a retirement decision, for example, "need more time to care for someone (parent, child, spouse, other)." They were answered on the same four-point $(1,=$ "not important," to 4 , = "very important,") scale as the work-related factors described above.

Additionally, through brainstorming, talking to retirees, and previous literature on retirees' activities (e.g., especially Ball and Francosky, 1988), a list of 16 retirement activities was developed. Employees were asked how often they expect to engage in each activity after they retire. Based on factor analysis (Beehr and Nielson, 1995), five expected retirement activity variables were formed: social activities $(\alpha=.65$, test-retest $r=.64)$, growth activities $(\alpha=.59$, test-retest $r=.68$ ), passive activities ( $\alpha=.44$, test-retest $r=.49)$, tinkering activities $(\alpha=.41$, test-retest $r=.62)$, and employment activities $(\alpha=.72$, test-retest $r=.58$ ). Example items from each of these indices are "getting together with friends," "taking classes," "watching television," "work around your own home," and "working for pay full-time," respectively. The five-point response scale had the following labels: 1, "never;" 2, "rarely;" 3, "sometimes;" 4, "often;" and 5, "very often." The alphas were somewhat low, but this may be due to the fact that each index contained only about three items. The factor analysis had resulted in a relatively "clean" or simple structure. The median loading of items on their assigned factors was .65 , and the median loading on other factors was .10. As with the JDS variables, participants were asked about their retirement activities about 6 months later. The correlations of these indices measured before and after retirement were taken as a form of test-retest reliability (reported above), although the first reports of retirement activities were reports of expected future retirement activities, while the second reports were of current, actual retirement activities. Social, growth, tinkering, and employment activities were reported to occur with significantly less frequency after retirement 
than they had been predicted to occur in the preretirement report (Beehr and Nielson, 1995). The mean differences and lower correlations in the cross-time data were probably due in part to the changed nature of the variables (future predictions versus current activities) at the two time periods.

The controls. Gender, wealth, and health were used as control variables, because they have often been found related to retirement (Brown, Fukunaga, Umemoto, and Wicker, 1996). Wealth was measured by a combination of information obtained from the employee questionnaire consisting of expected payouts from the state retirement fund and social security and personal savings and other assets. These were combined with life expectancy in a formula to form a wealth variable consistent with the economics approach advocated by Burkhauser and Quinn (1983a, b; Quinn, Burkhauser, and Myers, 1990). For example, economists propose that the worker facing a retirement decision chooses between two different streams of income and treats pension rights as an asset whose value changes with the age of retirement (because the likely number of years the person will live and require income varies inversely with age of retirement). The wealth variable therefore reflected the level of predicted income and financial security in retirement.

Health was measured with a two-item index, one from the employee's questionnaire ("my health is excellent") and one from the spouse's questionnaire ("my spouse's health is excellent"), answered on five-point Likert scales with the points labeled 1, "strongly disagree;" 2, "disagree;" 3, "neither agree nor disagree;" 4, "agree;" and 5, "strongly agree." The employee and spouse reports of the employee's health were positively correlated $(r=.70)$, and the difference between the mean scores on the two variables was small (.04) and nonsignificant.

Gender was obtained from personnel records.

\section{Analyses}

Several analyses were used to determine the relationships of the work and nonwork predictors with retirement age. First, zero-order correlations were calculated to show the simple relationships between the 15 separate predictors and retirement age. Then, 3 commonly studied retirement predictors (health, wealth, and gender) were controlled via hierarchical regression to examine the strength of all work and nonwork variables' relationship as a set with retirement age. Finally, two separate hierarchical multiple regressions of retirement age on the work-related predictor variables and on the nonwork-related predictor variables were calculated. The $R^{2}$ from each of these was compared with the $R^{2}$ from the first multiple regression (with all predictors) in order to show the unique predictive power of work and of nonwork variables over and above the effects of the other.

\section{RESULTS}

Means, standard deviations, and correlations are presented in Table 1. Significant zero-order correlations were obtained between criterion, predictor, and 


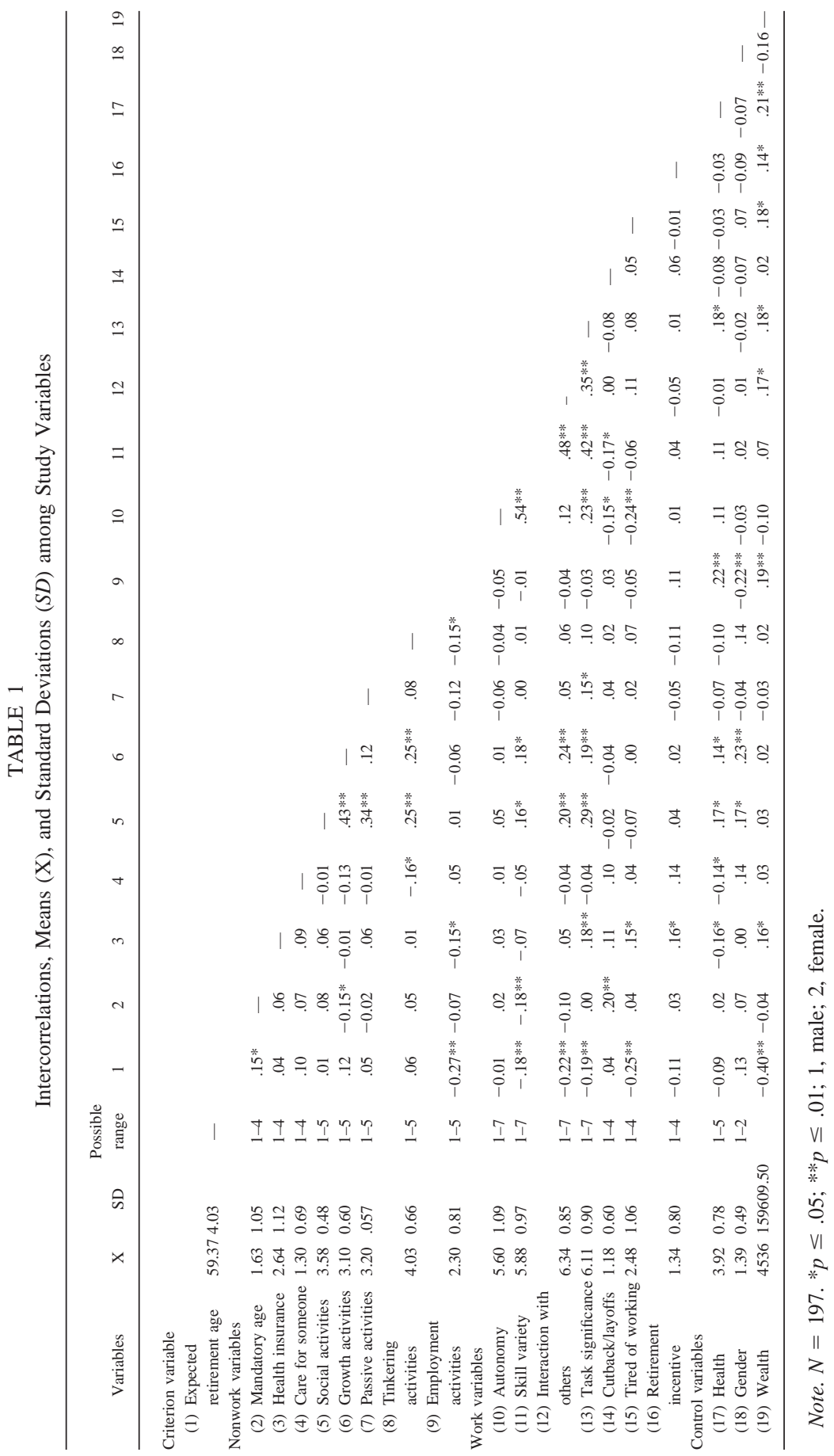


control variables. The only control variable to correlate with the criterion, expected retirement age, was wealth $(r=-0.40)$; health and gender did not correlate with the criterion. Nevertheless, these variables were held constant in subsequent hierarchical multiple regression analyses in accordance with earlier research evidence and our a priori analysis plan. As noted earlier, finances have been the most consistent predictors of retirement in prior research.

The first, most simple answer to the research question of what work and nonwork variables predict retirement age is provided by these correlations. Of the study's main predictor variables, five correlated negatively with expected age of retirement: expecting to engage in other employment activities after retiring, job skill variety, interaction with others at work, task significance, and being tired of working. The latter four are work-related variables, whereas the first one listed is a non-work-related variable. One other nonwork variable, reaching mandatory retirement age, correlated positively with expected retirement age. Further, because gender and needing to care for someone had a complex relationship with retirement in past research (Talaga and Beehr, 1995), we also tested the interaction of these two variables for predicting retirement age. The interaction was not significant, however, and therefore it was not included in subsequent analyses of the data.

Hierarchical multiple regressions were calculated to show the joint and separate effects of work and nonwork predictors on retirement age while controlling for health, wealth, and gender. Three separate multiple regressions were calculated and are presented in Table 2 as three models. The first model included all the predictor variables after the control variables (gender, wealth, and health) were entered. In the second model, the variance explained by the work-related variables only, again after controlling for gender, wealth, and health, was examined. Finally, variance accounted for in expected age of retirement was examined by entering the control variables followed by the nonwork variables only in the third model.

The first regression model, which included all work and nonwork predictor variables and control variables, yielded a multiple $R$ of $0.60, F(19,179)=5.43$. In step one, the variable set of respondents' gender, wealth, and health proved to be a significant predictor of expected retirement age. Together, these three control variables accounted for $17 \%$ of the variance (adjusted $R^{2}=16 \%$ ). However, when entering the work and nonwork variables, an additional $20 \%$ of the variance was accounted for in the criterion (Table 2).

The betas in the overall multiple regression in the first part of Table 2 allow comparison across predictors, because the betas represent the results for standardized variables. An examination of the betas revealed that the variables, wealth (a control), "reaching mandatory retirement age" (nonwork), "availability and cost of continued health insurance" (nonwork), "being tired of working" (work), "need more time to care for someone" (nonwork), expected future employment activities (nonwork), and expected growth activities (nonwork) were significant predictors. Moreover, based on the directional signs of the betas, 
TABLE 2

Summary of Hierarchical Regression Analysis of Control Variables and Predictor Variables on Expected Age of Retirement $(N=197)$

\begin{tabular}{|c|c|c|c|c|c|c|c|}
\hline Variable & $B$ & $S E B$ & $\beta$ & Adjusted $R^{2}$ & $R$ & $R^{2}$ & $\Delta R^{2}$ \\
\hline \multicolumn{8}{|l|}{ All models } \\
\hline Step 1 & & & & .16 & $.41^{*}$ & $.17^{* * *}$ & \\
\hline Gender & .56 & .55 & .07 & & & & \\
\hline Wealth & -9.89 & 1.70 & $-0.39 * *$ & & & & \\
\hline Heath & -0.02 & .35 & -0.003 & & & & \\
\hline \multicolumn{8}{|l|}{ Model 1-All predictors } \\
\hline Step 2 & & & & .30 & $.60^{*}$ & $.36^{* *}$ & $.20 * *$ \\
\hline Gender & -0.26 & .55 & -0.03 & & & & \\
\hline Wealth & -7.87 & 1.69 & $-0.31 * *$ & & & & \\
\hline Health & .31 & .35 & .06 & & & & \\
\hline Passive activities & .18 & .47 & -0.75 & & & & \\
\hline Mandatory age & .54 & .25 & $.14 *$ & & & & \\
\hline Skill variety & -0.37 & .36 & -0.09 & & & & \\
\hline Retirement incentive & -0.44 & .32 & -0.09 & & & & \\
\hline Tinkering activities & .30 & .40 & .05 & & & & \\
\hline Tired of working & -0.89 & .25 & $-0.23 * *$ & & & & \\
\hline Cutback/layoffs & -0.06 & .42 & -0.01 & & & & \\
\hline Care for someone & .92 & .37 & $.16^{* *}$ & & & & \\
\hline Health insurance & .46 & .24 & $.13^{*}$ & & & & \\
\hline Employment activities & -0.96 & .32 & $-0.19 * *$ & & & & \\
\hline Growth activities & 1.54 & .48 & $.23 * *$ & & & & \\
\hline Task significance & -0.47 & .32 & -0.11 & & & & \\
\hline Interaction with others & -0.48 & .35 & -0.10 & & & & \\
\hline Autonomy & -0.12 & .28 & -0.03 & & & & \\
\hline Social activities & -0.56 & .65 & -0.07 & & & & \\
\hline \multicolumn{8}{|l|}{ Model 2-Work variables } \\
\hline Step 2 & & & & .20 & $.50^{*}$ & $.25 * *$ & .08 \\
\hline Gender & .76 & .54 & & & & & \\
\hline Wealth & $-8.00 * *$ & 1.76 & & & & & \\
\hline Health & -0.02 & .35 & & & & & \\
\hline Cutback/layoffs & .28 & .44 & & & & & \\
\hline Retirement incentive & -0.30 & .33 & & & & & \\
\hline Interaction with others & -0.36 & .37 & & & & & \\
\hline Tired of working & $-0.76^{* * *}$ & .26 & & & & & \\
\hline Autonomy & .01 & .30 & & & & & \\
\hline Task significance & -0.16 & .33 & & & & & \\
\hline Skill variety & -0.48 & .38 & & & & & \\
\hline \multicolumn{8}{|l|}{ Model 3-Nonwork variables } \\
\hline Step 2 & & & & .22 & $.51 *$ & $.26^{* *}$ & .09 \\
\hline Gender & -0.24 & .58 & & & & & \\
\hline Wealth & $-9.92 * *$ & 1.71 & & & & & \\
\hline Health & .26 & .36 & & & & & \\
\hline Passive activities & .18 & .49 & & & & & \\
\hline Mandatory age & $.54 *$ & .25 & & & & & \\
\hline Tinkering activities & .26 & .42 & & & & & \\
\hline Health insurance & .22 & .24 & & & & & \\
\hline Care for someone & $.84 *$ & .39 & & & & & \\
\hline Employment activities & $-0.88 * *$ & .34 & & & & & \\
\hline Growth activities & $1.20 *$ & .50 & & & & & \\
\hline Social activities & -0.75 & .66 & & & & & \\
\hline
\end{tabular}

Note. $* p \leq .05 ; * * p \leq .01$. 
those planning to engage in other employment activities and those simply tired of working appear to retire at younger ages, while those who were planning to engage in growth activities, such as acquiring additional education or those needing to care for someone, plan to retire at older ages. In addition, employees expect to retire at a later age as the importance of the availability and cost of continued health insurance increases.

For the second and third regression analyses, work variables accounted for an additional $8 \%$ of the variance and nonwork variables accounted for an additional $9 \%$ of the variance above and beyond the control variables (see Table 2). Controlling for gender, health, and wealth, the only work-related variable that appeared to predict retirement age is "being tired of working." Apparently, and quite logically, the more tired one is of working the more likely it is that he or she will retire earlier. As for the nonwork factors, reaching mandatory retirement age, needing to care for someone, and expecting to engage in growth activities and employment activities after retirement all predicted expected retirement age.

\section{Unique Effect of Each Set of Variables}

An overall issue addressed in the study is the special contribution of the sets of work-related and nonwork-related variables to the retirement decisions. This was addressed by comparing the $R^{2}$ s of specific sets of predictors in Table 2. By subtracting the $R^{2}$ or percentage of variance accounted for by the work-related variables in Table $2(.25)$ from the $R^{2}$ of the whole set of variables (.36), it is seen that the other variables-the non-work-related predictors-account for .11 or $11 \%$ of the variance in age of retirement over and above the work-related predictors. Computing a similar subtraction of the $R^{2}$ for non-work-related predictors from the $R^{2}$ for all predictors $(.36-.26=.10)$ shows that the work-related predictors account for $10 \%$ of the variance in retirement age. Thus, both work and nonwork variables seem important in retirement decisions, because each set of predictors makes a unique contribution to the prediction of retirement age of about $10 \%$ of the variance.

\section{DISCUSSION}

This study sought to determine whether work environment characteristics could act to push people out of the workplace and into retirement and whether expectations of retirement activities and situations could entice them to retire at earlier ages. It appears that both work-related and non-work-related factors can influence retirement decisions. This basic idea, that factors in both work and nonwork categories can lead to retirement decisions, is strikingly paralleled in models of another work withdrawal behavior, absenteeism (e.g., Steers and Rhodes, 1978). Furthermore, the combination of these two life domains has a greater influence than either one alone, i.e., they predict unique variance in the ages at which people decide to retire. 
Because finances have been a consistent predictor of retirement decisions in previous research, wealth was held constant in the hierarchical regression analyses. As expected, wealth did predict retirement age. However, health, which has probably been the second most consistent predictor (though much weaker than finances; Talaga and Beehr, 1989; Taylor and Shore, 1995), and gender did not predict unique variance in expected retirement age in the three models. The entire Model 1 regression analyses showed that a larger number of the nonwork variables (five of eight) predicted retirement age than work-related variables (one of seven). In other words, more elements of life outside the workplace were predictors of the retirement criterion than attitudes and perceptions about the workplace itself. This might suggest that employees contemplating retirement are forward-looking, that is, they are pulled toward retirement more by what they believe awaits in the future after retirement than pushed away from work by thoughts of the current workplace. This conclusion must be tempered, however, by the fact that the effect size, or percentage of variance accounted for by the set of work-related variable(s) in Model 2 of Table 2 was almost as large as the effect size of the set of nonwork variables in Model 3 of Table 2 (.08 versus .09).

\section{Work Characteristics as Inducements to Retire}

Only one characteristic related to work, "being tired of working," predicted retirement after controlling for gender, wealth, and health of the employee in Model 2. The direction of the beta for "being tired of working" was negative, suggesting that employees will retire sooner when they are tired of working. Intuitively and logically this makes sense. Moreover, this variable resembles a single item that was the best predictor in McCune and Schmitt's (1981) study that asked respondents "how much they wanted to work" (p. 802). The other workrelated predictor variables did not add significantly to the criterion. McCune and Schmitt, however, had found that some job characteristics similar to those in the present study added significant variance to the prediction of retirement status. Future research should try to replicate and explain this inconsistent finding.

The zero-order correlations of the jobs' variety, required interaction with others, and task significance with age of retirement were negative, indicating that people in jobs with these characteristics were more likely to retire younger. This is the opposite of McCune and Schmitt's (1981) results, the only other study of such variables in relation to retirement decisions. One study conceived a similar set of job characteristics as "complexity," argued that it could be stressful, and showed that it was positively related to cardiovascular illness among Type A but not Type B people (Schaubroeck, Ganster, and Kemmerer, 1994). If these job characteristics are stressful, they might induce people to retire, although that link could not be assessed in the present data. There appears to be a complex relationship between job characteristics and retirement, and future research should examine them in combination with cardiovascular disease and Type A behavior among older employees. 


\section{Expected Retirement Situations as a Draw toward Retirement}

In Model 3, after wealth predicted the decision to retire younger, expectation of working for pay after retirement also predicted earlier retirement. Taken together with results for wealth, this makes the expectation of having good finances in retirement a strong inducement for people to retire.

The idea of working for pay after one retires also has important implications for the definition of retirement. It has been noted that there are varying definitions of retirement and that there may also be varying degrees of retirement within each definition (reviews by Beehr, 1986; Talaga and Beehr, 1989). If retirement means leaving the workforce, for example, then by definition, one cannot retire and still be working for pay. It has been noted, however, that retirement involving the permanent withdrawal from the workforce was more typical before the 1970s than it is now (Hayward, Cummins, and Wray, 1994). Obviously, in this study, retirement is defined as leaving a specific job and organization in a way that both parties decide to label retirement and in a way that the retiree receives some compensation (e.g., pensions) that is only provided to retirees, so defined. This is a common operationalization of retirement in the research, one labeled "pension retirement" in Talaga and Beehr (1995). The several differing definitions of retirement were not investigated here, but this finding regarding working after retirement suggests the reality of "pension retirement" as one definition.

Feldman's (1994) definition of retirement, noted earlier, does not require exiting from the workforce entirely. This is because many older workers retire and then work again. This postretirement work may come immediately after retirement or later, be part-time or full-time, and be in a similar or different occupation. Jobs that people take after retirement are often called "bridge" jobs, because they span the time from a career-type, long-term job to full withdrawal from work (Doeringer, 1990). They are more common than is generally known; more than half of older United States retirees have such jobs at some point in their postcareer lives (Ruhm, 1990). Some retirees, after a period out of the work force, reenter it. Ruhm (1990) dubbed this "reverse retirement." Little is known for certain about these postretirement jobs (Doeringer, 1990), but most are in different occupations and industries from the retirees' career jobs, and most pay less and have lower status than the career jobs had (Doeringer, 1990). Future research might be aimed at bridge jobs, in order to determine, for example, whether the same work and nonwork factors influencing people to retire also influence them to work for pay after retirement.

In addition to the effects of working for pay, people appear less likely to retire if they expect that retirement will bring frequent occasions to engage in growth activities (these included volunteer work or religious activities, reading, participating in organizations or clubs, and taking classes). Considering that this was a relatively well-educated sample, one might have expected the growth-type activities to be attractive. If these predictors have a causal influence, and employees associate these activities with getting "old," however, then there could 
actually be some tendency to avoid these activities by remaining in the current job. Alternatively, it may be that, if employees want continued growth activities, they might just as well stay on the job and get paid for them. The idea that income is an issue fits with the negative relationship of employment activities with expected retirement age; if the employee expects to work for pay after retirement, he or she retires sooner. At any rate, such growth activities do not appear to pull older employees toward retirement. This may mean that a perhaps idealized view of retirement in which one finally has time to develop one's self and grow psychologically is not particularly attractive to most people.

Two other variables that positively predicted expected retirement age were "reaching mandatory retirement age" and "needing more time to care for someone." At the time data were collected, the legal prohibition against mandatory retirement age in the United States was already a decade old. Perhaps older employees may be less likely to know the amendment than younger employees, or perhaps the older employees may simply have believed that it was "time" to retire. Alternatively, they may have felt some kind of unofficial pressure to retire at a certain age. Finally, with respect to "needing more time to care for someone," older employees probably have elderly spouses who may be in need of more attention and therefore need to leave-more so than younger employees, who probably have younger, and by extension potentially healthier, spouses. The measure of needing to care for others referred to "parent, child, spouse, other," rather than solely spouses, however. The questionnaire also contained one item asking for the employees' perceptions of their spouses' health, and this item correlated negatively $(r=-0.32, p<.01)$ with the need to care for others. This is consistent with the idea that the need to care for a spouse was a significant part of this reason for retiring. Because this correlation was only moderately strong, however, it is possible that the need to care for still other people, e.g., aging parents, also played a role.

\section{Limitations}

A limitation of the study may be its generalizability. This was not a national cross section of older employees, but was a sample of married, somewhat well-educated, older employees of a state government. The extent to which the results generalize to other groups is unknown at this time, and it must be left to future research to determine that.

A second limitation is that the study's nonexperimental methods cannot establish causality. Although we desire to know what causes retirement, we can only find relationships in these data, and we must rely on theory and reasoning to argue that the relationships are causal.

Third, there are limitations due to the measures used. For example, even though the JDS measures of job characteristics have a long history of use establishing their reliability and validity, some of its scales' alpha reliabilities were low. The test-retest reliabilities lent confidence in their use, however. The only other set of measures for which test-retest reliabilities were available, the 
expected retirement activities, mirrored this situation of weak internal consistency but good test-retest reliabilities. In addition, the factor analysis reported in Beehr and Nielson (1995) indicated good discrimination among the indices.

There also can be a concern regarding the three work-related (retirement incentives from the employer, workforce reductions, and being tired of working) and the three non-work-related predictors (needing to care for someone, availability of health insurance, and reaching mandatory retirement age) for which people were asked their importance in the decision to retire. First, these measures were single items, which might have weakened their reliability. Second, these items were different in nature from the other predictors in one specific way. They asked employees to tell the degree to which these factors were a cause of their retirement decisions, while the other measures asked employees simply to describe their work or nonwork situations. For the study's main purpose of comparing the two domains of work and nonwork predictors of retirement, however, neither of these limitations may have mattered very much, because there were exactly the same number of these types of measures (three) in each domain.

Finally regarding the measures, there might be limitations in interpreting the results if there were reduced variance on the predictors due to homogeneity of the sample. The participants were all employed in the same state employment system, but they had different jobs, making it less likely that variance in the measures was greatly reduced due to having a single employer. For the JDS job characteristics variables, however, normative data show that the standard deviations, within occupations but across organizations, tend to be a little above 1.0, while the standard deviations in the present study tended to be a little below 1.0. Therefore, there may have been some homogeneity on these variables. Looking at the standard deviations and the possible ranges of the variables (Table 1), the sample might have the most homogeneity on expected social and passive retirement activities. Neither of these variables was related to the criterion of age at retirement, and so the results could be affected by such homogeneity.

\section{Summary}

There are several important results of this study. First, wealth was, as in virtually all previous research on retirement, a predictor of retirement decisions. Health was not, however, a predictor of retirement decisions, although it has been a popular and fairly common predictor in past studies. Second, even when holding wealth constant (as well as health and gender), elements of both the work environment and expected retirement situations were related to retirement decisions. Neither the push of the job nor the pull of retirement appeared to be a stronger predictor than the other overall, however, as the additional variances accounted for in the criterion variable, beyond the control variables, were practically equivalent.

The discovery that perceived job characteristics do not independently influence expected retirement age was unexpected and inconsistent with the only 
similar study to date (McCune and Schmitt, 1981). Obviously this is an underresearched topic. Although three of the four job characteristics had significant correlations with retirement, none had significant regression weights after wealth was controlled. The fact that only two of five expected retirement activities had a significant influence on expected retirement age is counterintuitive to our beliefs that retirement activities may be viewed as especially enticing or attractive. Furthermore, the fact that one of the two, growth activities, was positively related to retirement age suggests that it may actually dissuade employees from retiring rather than entice them to retire.

These findings indicate that little is truly known about how jobs and outside activities affect retirement decisions and suggest the need for future research. As noted earlier, both society at large and each individual organization have a stake in understanding and predicting retirements. The current national political debate about the funding of social security illustrates the former, and the phenomenon of organizations periodically offering retirement incentives illustrates the latter. The present study helps by investigating an important but rarely considered comparison of influences on retirement, work and nonwork influences.

Future research could increase our knowledge of this issue in several ways. First, these results come from a sample of relatively well educated older employees, and it would be useful to discover whether they apply equally well to other sectors of the elderly labor force. Less educated people might have different motivations to stay on or leave their jobs. Their job characteristics and their outside interests and life styles might be systematically different, and research could examine the degree to which that affects their retirement decisions.

Second, as noted earlier, occupational stress might impact some decisions to retire. Turnover and absenteeism have been shown to be predicted by workplace stressors (e.g., Gupta and Beehr, 1979), but we do not know whether workers who are eligible to retire might also use retirement to escape stressful work. In relation to stressful work, the personal characteristic of Type A behavior might also predict retirement decisions. It has been observed that some Type A people seek stressful situations (e.g., Ganster, 1987); they might actually want to hold on to a pressure-packed job rather than retire, for example.

Third, a persistent problem with retirement research is the definition of the criterion, retirement. Bridge employment can entail retirees working in the same job part-time; working in a new job, career, or industry either part- or full-time; and working for pay beginning immediately after retirement from one's career job or reentering the workforce after a period of not working at all for pay (Doeringer, 1990a). There is probably a continuum of the degree of retirement (Beehr, 1986). People with bridge employment are partially retired. Partial retirement has been studied relatively little (Ruhm, 1990), and research is needed to explain (1) who can take this retirement option, (2) who does take it, and (3) why. The apparently increasing phenomenon of bridge employment and partial retirement was a primary reason that Feldman (1994) found it necessary to include "reduced psychological commitment to work" (p. 287) in his definition 
of retirement, rather than total withdrawal from paid work. Future research on retirement decisions should also study this psychological variable, both among people who are approaching retirement and among those who are apparently already retired but working in bridge employment.

\section{REFERENCES}

Adams, G. A., \& Beehr, T. A. (1998). Turnover and retirement: A comparison of their similarities and differences. Personnel Psychology, 51, 643-665.

Ball, G. T., \& Francosky, M. D. (1988). The Travelers 1988 Retirement Survey: Retirees' views of work and retirement. Hartford, CN: The Travelers Companies.

Beehr, T. A. (1986). The process of retirement. Personnel Psychology, 39, 31-55.

Beehr, T. A., \& Nielson, N. L. (1995). Descriptions of job characteristics and retirement activities during the transition to retirement. Journal of Organizational Behavior, 16, 681-690.

Brown, M. T., Fukunaga, C., Umemoto, D., \& Wicker, L. (1996). Annual review, 1990-1996: Social class, work, and retirement behavior. Journal of Vocational Behavior, 49, 159-189.

Burkhauser, R. V., \& Quinn, J. F. (1983a). The effect of pension plans on the pattern of life cycle compensation. In J. E. Triplett (Ed.), The measurement of labor cost (pp. 395-415). Chicago: The Univ. of Chicago Press.

Burkhauser, R. V., \& Quinn, J. F. (1983b). Is mandatory retirement overrated? Evidence from the 1970s. Journal of Human Resources, 18, 337-358.

Cotton, J. L., \& Tuttle, J. M. (1986). Employee turnover: A meta-analysis and review with implications for research. Academy of Management Review, 11, 55-70.

Doeringer, P. B. (1990a). Bridges to retirement: Older workers in a changing labor market. Ithaca, NY: Cornell Univ. ILR Press.

Doeringer, P. B. (1990b). Economic security, labor market flexibility, and bridges to retirement. In P. B. Doeringer (Ed.), Bridges to retirement: Older workers in a changing labor market (pp. 3-22). Ithaca, NY: Cornell Univ. ILR Press.

Erdner, R. A., \& Guy, R. F. (1990). Career identification and women's attitudes toward retirement. International Journal of Aging and Human Development, 30, 129-139.

Feldman, D. C. (1994). The decision to retire early: A review and conceptualization. Academy of Management Review, 19, 285-311.

Fullerton, H. N. (1991). Labor force projections: The baby boom moves on. Monthly Labor Review, 114, 31-44.

Ganster, D. C. (1987). Type A behavior and occupational stress. In J. M. Ivancevich \& D. C. Ganster (Eds.), Job stress: From theory to suggestion (pp. 61-84). New York: Haworth.

Gibson, R. (1993). The black American retirement experience. In J. S. Jackson, L. M. Chatters, \& R. J. Taylor (Eds.), Aging in black America (pp. 277-297). Newbury Park, CA: Sage.

Gupta, N., \& Beehr, T. A. (1979). Job stress and employee behaviors. Organizational Behavior and Human Performance, 23, 373-387.

Hackman, J. R., \& Oldham, G. R. (1976). Motivation through the design of work: Test of a theory. Organizational Behavior and Human Performance, 16, 250-279.

Hackman, J. R., \& Oldham, G. R. (1980). Work redesign. Reading, MA: Addison-Wesley.

Hanisch, K. A., \& Hulin, C. L. (1990). Job attitudes and organizational withdrawal: An examination of retirement and other voluntary withdrawal behaviors. Journal of Vocational Behavior, 37, $60-78$.

Hanisch, K. A., \& Hulin, C. L. (1991). General attitudes and organizational withdrawal: An evaluation of a causal model. Journal of Vocational Behavior, 39, 110-128.

Hayward, M. D., \& Hardy, M. A. (1985). Early retirement processes among older men. Research on Aging, 7, 491-515. 
Hayward, M. D., Cummins, E. M., \& Wray, L. A. (1994). The relationship between retirement life cycle changes and older men's labor force participation rates. Journal of Gerontology: Social Sciences, 49, S219-S230.

Lawson, K. (1991). What happened to normal retirement age? Employee Benefit Plan Review, 46, $12-15$.

McCune, J. T., \& Schmitt, N. (1981). The relationship between job attitudes and the decision to retire. Academy of Management Journal, 24, 795-802.

Nielson, N. L., \& Beehr, T. A. (1994). Retirement income for surviving spouses. Public Personnel Management Journal, 23, 407-428.

Quinn, J. F., Burkhauser, R. V., \& Myers, D. A. (1990). Passing the torch: The influence of economic incentives on work and retirement. Kalamazoo, MI: Upjohn Inst.

Robinson, P. K., Coberly, S., \& Paul, C. E. (1985). Work and retirement. In R. H. Binstock \& E. Shanas (Eds.), Handbook of aging and the social sciences (pp. 503-527). New York: Van Nostrand-Reinhold.

Ruhm, C. J. (1990). Career jobs, bridge employment, and retirement. In P. B. Doeringer (Ed.), Bridges to retirement: Older workers in a changing labor market (pp. 92-110). Ithaca, NY: Cornell Univ. ILR Press.

Schaubroeck, J., Ganster, D. C., \& Kemmerer, B. E. (1994). Job complexity, “Type A” behavior, and cardiovascular disorder: A prospective study. Academy of Management Journal, 37, 426-439.

Shultz, K. S., Morton, K. R., \& Weckerle, J. R. (1998). The influence of push and pull factors on voluntary and involuntary early retirees' retirement decision and adjustment. Journal of Vocational Behavior, 53, 45-57.

Steers, R. M., \& Rhodes, S. R. (1978). Major influences on employee attendance: A process model. Journal of Applied Psychology, 63, 391-407.

Stetz, T. (1998). Reasons for retirement: Antecedents and consequences. Unpublished doctoral dissertation, Central Michigan Univ., Mt. Pleasant.

Sum, A. M., \& Fogg, W. N. (1990). Profile of the labor market for older workers. In P. B. Doeringer (Ed.), Bridges to retirement: Older workers in a changing labor market (pp. 33-63). Ithaca, NY: Cornell Univ. Press.

Talaga, J. A., \& Beehr, T. A. (1989). Retirement: A psychological perspective. In C. L. Cooper \& I. Robertson (Eds.), International review of industrial and organizational psychology (pp. 185-211). Chichester: Wiley.

Talaga, J. A., \& Beehr, T. A. (1995). Are there gender differences in predicting retirement decisions? Journal of Applied Psychology, 80, 16-28.

Taylor, M. A., \& Shore, L. M. (1995). Predictors of planned retirement: An application of Beehr's model. Psychology and Aging, 10, 76-83.

Received: March 23, 1999 